\title{
METODOLOGIA PARA ELABORAÇÃO DE MATRIZ CURRICULAR: INTEGRAÇÃO E TRANSVERSALIDADE
}

\author{
Araci Hack Catapan ${ }^{1}$ \\ Clovis Nicanor Kassick ${ }^{2}$ \\ Walter Ruben Iriondo Otero ${ }^{3}$
}

\section{RESUMO}

No mundo do trabalho, a formação profissional tem sido um desafio constante, cada vez mais implicado nos avanços técnico-científicos, especialmente dos sistemas de informação e comunicação. Este artigo apresenta resultados de uma investigação realizada na aplicação de uma metodologia de elaboração de Matriz Curricular de Referência. Teve como objeto de estudo 53 Cursos de Educação Profissional Técnica de Nível Médio do sistema Escola Técnica Aberta do Brasil. 0 objetivo da pesquisa foi validar uma metodologia de organização curricular integrada e transversal. A metodologia de investigação foi a pesquisa-ação, observando os princípios teórico-metodológico do processo de construção coletiva para Resolução de Problemas. Essa investigação foi realizada pelo grupo de Pesquisa Científica em Educação a Distância (PCEADIS/CNPq), e desenvolvida por uma rede de pesquisa que reúne 76 pesquisadores, no período de 2009 a 2014. Os instrumentos utilizados foram um protocolo de registro online e uma matriz composta por quatro categorias básicas: o perfil do egresso, as competências, as bases tecnológicas e os componentes curriculares. A teoria que sustenta a proposta é a organização curricular integrada e transversal. Como resultados foram elaboradas, aprovadas e publicadas 53 matrizes curriculares que servem de referência para atualizar ou criar novos projetos para oferta dos cursos de Formação Profissional Tecnológica. Os resultados evidenciam a efetividade de uma organização curricular integrada e transversal. Esta investigação tem um desdobramento que está sendo finalizado pela mesma rede, organizada em oito grupos de pesquisadores, que se propõem a investigar, acompanhar e avaliar as implicações deste estudo na Rede e-Tec Brasil. Este projeto de investigação tem financiamento do FNDE/MEC.

Palavras-chave: Matriz curricular de referência; Formação Profissional; integração; transversalidade.

\section{METODOLOGÍA PARA ELABORACIÓN DE MATRIZ CURRICULAR: INTEGRACIÓN Y TRANSVERSALIDAD}

\footnotetext{
1 Pós-doutorado - em Memoria organizacional, inovação social e resiliência, pelo centro ALGORITMI/UMINHO/PT (2016); doutorado em Engenharia de Produção - pela Universidade Federal de Santa Catarina (2001). Atualmente é professora na Universidade Federal de Santa Catarina nos programas de PósGraduação em Engenharia e Gestão do Conhecimento e em Educação. Atua em pesquisa, ensino e extensão, com ênfase nos seguintes temas: E-learning, cibercultura, Tecnologia de comunicação digital (TCD), educação virtual, Educação a Distância formação de professores, Recursos educativos abertos. Consultora UAB/CAPES e Rede e-Tec Brasil/MEC. É coordenadora dos grupos de pesquisa: Habitats de Inovação e Empreendedorismo e Pesquisa Científica em E-learning do CNPq/MEC. E-mail: <aracihack@gmail.com>

2 Doutorado em Educação pela Universidade Estadual de Campinas-UNICAMP (2001). Professor Adjunto II aposentado da UFSC, atualmente é professor da Universidade do Sul de Santa Catarina-UNISUL, no Curso de Pedagogia e no Programa de Pós-Graduação-Mestrado em Educação. É pesquisador do grupo GTMC-UFSC, na pesquisa: Elaboração de Currículos Referência para os Cursos Técnicos da Escola Técnica Aberta do Brasil/ eTec Brasil, do E-TEC/SETEC/MEC. E-mail: <kassickclovis@gmail.com>

3 Doutorado em Engenharia e Gestão do Conhecimento pela Universidade Federal de Santa Catarina, Brasil(2008). Professor Adjunto da Universidade Federal de Pelotas , Brasil. E-mail: <wiriondo@gmail.com>
} 


\title{
RESUMEN
}

En el mundo del trabajo, el entrenamiento profesional hay sido un desafío constante a cada vez más implicando avances técnico-científicos, especialmente de los sistemas de información y comunicación. Este artículo presenta resultados de una investigación realizada con la aplicación de una metodología de elaboración de Matriz Curricular de Referencia. Tuve como objeto de estudio 53 Cursos de Educación Profesional Técnica de Nivel Medio del sistema Escuela Técnica Abierta de Brasil. El objetivo de la investigación fue validar una metodología de organización curricular integrada y transversal. La metodología de investigación fue la investigación-acción, observando los principios teóricos y metodológicos del proceso de construcción colectiva para Resolución de Problemas. Esa investigación fue realizada por el grupo de Investigación Científica en Educación a Distancia (PCEADIS/CNPq), y desarrollada por una red de investigación que reúne 76 investigadores, en el período de 2009 hasta 2014. Los instrumentos utilizados fueron um protocolo de registro en línea y una matriz compuesta por cuatro categorías básicas: el perfil del egreso, las competencias, las bases tecnológicas y los componentes curriculares. La teoría que sustenta la propuesta es la organización curricular integrada y transversal. Como resultados fueron elaboradas, aprobadas y publicadas 53 matrices curriculares que sirven de referencia para ofrecer cursos de Formación Profesional Tecnológica, actualizar o crear nuevos proyectos para ofrecer cursos de Formación Profesional Tecnológica. Los resultados evidencian la efectividad de una organización curricular integrada y transversal. Esa investigación tiene desdoblamiento que va a ser finalizado por la misma red, organizada en ocho grupos de investigadores que se proponen a investigar, acompañar y evaluar las implicaciones de ese estudio en la Red e-Tec Brasil. Este proyecto de investigación tiene aporte financiero de FNDE/MEC.

Palabras-clave: Matriz curricular de referencia; Entrenamiento Profesional; integración; transversalidad.

\section{METHODOLOGY FOR THE PREPARATION OF CURRICULAR MATRIX: INTEGRATION AND TRANSVERSALITY}

\begin{abstract}
In the work's world, the professional training has been a constant challenge increasingly involved with technical and scientific advances, especially the information and communication systems. The paper presents results of a research carried out through the application of a methodology for preparing a Curricular Matrix of Reference. The aim was to study 53 Courses of High School Technical-Professional Education of the Open and Technical School system of Brazil. The objective was to validate a methodology for an integrated and cross-curricular organization. The investigation method was the action-research, observing the theoretical-methodological principles of the collective construction process to the Problem-solving. The the group of Scientific Research in Distance Education (PCEADIS/CNPq) conducted investigation, and it was developed by a research network that brought together 76 researchers from 2009 to 2014. The instruments used were an online registration protocol and a matrix composed by four basic categories: the graduates' profile, skills, technological bases and curricular components. The theory behind the proposal is the integrated and cross-curricular organization. The results were elaborated, approved and published in 53 curricular matrices that serve as references for the provision of courses of TechnologicalProfessional Education, the projects upgrade or the creation of new ones. The results show the effectiveness of an integrated and cross-curricular organization. Another development of the research is going to be finalized by the same network, organized into eight groups of researchers that propose to investigate, monitor and evaluate the implications of this paper and the Network e-Tec Brazil. The FNDE/MEC funds the present investigation project.
\end{abstract}


Keywords: Curricular matrix of reference; professional training; integration; transversality.

As inovações técnico-científicas têm gerado transformações nos mais diversos setores do mundo do trabalho. No âmbito da formação profissional têm implicado, especialmente, nos modos de informação e comunicação, que constituem o eixo do processo de ensino-aprendizagem. O objeto que orienta todo e qualquer sistema de formação é a organização curricular. Neste estudo o currículo compreende, em primeiro lugar, o perfil desejado dos egressos e deste emerge a concepção filosófica, pedagógica e metodológica do curso. Essa concepção é o eixo desta pesquisa aplicada. Esta pesquisa responde a uma política educacional incentivada pelo Ministério da Educação endereçada ao sistema de Formação Profissional Técnica, no período de 2009 a 2014. Tem por objetivo elaborar Matrizes Curriculares de Referência para os cursos do Sistema e-Tec Brasil, aqueles ofertados na modalidade EaD (Educação a Distância), com a finalidade de promover a integração do sistema e equalizar a produção de materiais didáticos.

O Sistema e-Tec integra todos os cursos de formação profissional técnica de nível médio e do PROEJA ofertados na modalidade de Educação a distância na rede pública, e criados e aprovados no Edital 01/2007/SETEC/SEED. Esses cursos foram organizados a partir dos postulados dos Referenciais Curriculares Nacionais da Educação Profissional de Nível Técnico (2000), que se orientam pelas categorias teórico-práticas: competências, habilidades e bases tecnológicas definidas para cada área de atuação e pelo Catálogo Nacional de Cursos Técnicos (CNCT).

O CNCT surgiu de um estudo preliminar realizado em 2007, para orientar a organização do sistema de oferta $\mathrm{EaD}$ no ensino técnico. Esse estudo mostrou que o sistema de Formação Profissional Tecnológica desenvolvia-se em uma dispersão de 2.670 denominações de cursos técnicos de nível médio para um contingente de 7.940 ofertas de cursos (Censo Escolar, MEC/INEP, 2005). A Secretaria de Educação Profissional Tecnológica promoveu, então, a elaboração do Catálogo Nacional de Cursos Técnicos. Este catálogo reorganiza todo o contingente de cursos em 12 Eixos Tecnológicos, resultando em uma nominata de 155 cursos. Para cada curso define-se um perfil profissional e uma carga horária mínima (BRASIL, 2008). 
A pesquisa apresentada neste artigo tem como resultado a elaboração de uma abordagem teórico-metodológica aplicada para organização curricular para os cursos dos Sistema e-Tec ofertados na modalidade EaD. Participaram 72 pesquisadores organizados em rede Nacional, vinculados ao grupo de pesquisa PCEADIS/CNPq. Todos os pesquisadores estavam diretamente envolvidos com a elaboração de projetos pedagógicos para a oferta dos cursos para o sistema. Foram elaboradas 53 matrizes curriculares para os cursos que constituíam, naquele momento, o Sistema e-Tec, reunindo 47 instituições das esferas Federal e Estadual. O resultado imediato da pesquisa é a melhor sistematização dos cursos de Formação Profissional Técnica como um sistema integrado, expresso na elaboração das Matrizes Curriculares de Referência, que equaciona a formação geral e a formação profissional. Evidencia os pontos de integração do sistema pelos Eixos e a integração entre os cursos no Eixo. Internamente, a Matriz Curricular de cada curso integra a formação geral e a formação profissional pelas categorias teórico-práticas desenvolvidas: Perfil profissionaltécnico, Competências, Habilidades, e Bases Tecnológicas que se expressam nas Ementas.

Outro resultado imediato é a melhoria na sistematização para o processo de elaboração de materiais didáticos e de formação de professores-autores e professores formadores desses cursos, possibilitando uma organização mais sistemática, orgânica e econômica para o Sistema e-Tec Brasil. Este trabalho tem um projeto gráfico singular, pois comporta, em conteúdo e forma, uma concepção teórico-metodológica de outro modo de pensar e elaborar uma proposta curricular. Este modo de pensar tem como ponto de partida o perfil profissional do egresso e constitui definições de competências, habilidades, bases tecnológicas e ementas. A leitura adequada desta proposta requer um olhar vertical, horizontal e transversal de cada uma das partes, e do todo em todas as partes.

\section{A proposta metodológica: integração e transversalidade}

Trata-se de um trabalho com caráter metodológico orientado pelo modelo de pesquisa-ação, que tem como princípio de desenvolvimento a análise realizada pela técnica PBL (Problem based learning). Portanto, configura Concepção, apropriação e construção coletiva de uma proposta elaborada pelos seus próprios atores. 
A metodologia de trabalho desenvolvida não resulta em apenas um produto concluído e publicado, como acontece com os resultados da maioria das pesquisas. Seu resultado mais significativo é a transformação do objeto analisado no processo e a compreensão e utilização do mesmo pelos atores.

O presente estudo não é mais que um esforço coletivo que reúne os atores principais do acontecimento no reconhecimento da tecnologia em si, isto é, do reconhecimento de tudo que é criado e transformado pelo homem, como afirma Bourdieu (1987).

O espírito do trabalho é a construção coletiva para a integração dos Cursos em seus Eixos Tecnológicos por uma Matriz Curricular de Referência. Tomam-se, para orientar a organização e a análise, os seguintes elementos da organização curricular dos projetos de cursos aprovados: o perfil profissional, as competências, as habilidades, as bases tecnológicas e as ementas, conforme exposto no item anterior. Esta elaboração está ancorada em uma concepção de currículo que não se limita a uma grade curricular, mas à organização de todo o processo de implementação do curso: a concepção pedagógica, a população-alvo, a natureza da formação pretendida, a gestão das condições dadas e requeridas para o desenvolvimento do curso concernente com a modalidade de oferta, os processos de acompanhamento e avaliação. Este estudo elege e limita-se a um elemento dessa complexidade - a organização curricular - aqui denominada de Matriz Curricular de Referência (MCR).

Ao pensar currículo, vem à tela uma verdadeira ideografia dinâmica, uma concepção de mundo expressa em

[...] muitas coisas ao mesmo tempo: ideias pedagógicas, estruturação de conteúdos de uma forma particular, detalhamento dos mesmos, reflexo de aspirações educativas mais difíceis de moldar em termos concretos, estímulo de habilidades nos alunos, etc. Ao desenvolver uma prática concreta de modo coerente com quaisquer desses propósitos, o professor desempenha um papel decisivo (SACRISTÁN, 1998, p. 173).

É com essa compreensão que se desenvolve o estudo. Porém, para ser exequível dentre as contingências dadas e o complexo de definições, abordagens e propósitos, tomase um elemento fundamental e, nele e por ele, propõe-se perquirir, analisar, compreender, 
propor e superar a mera formalidade na organização e no desenvolvimento dos cursos de Formação Profissional Técnica do Sistema e-Tec Brasil. Fazer isso e, ao mesmo tempo, respeitar o que está instituído, a autonomia das instituições e as inúmeras possibilidades de interpretação que envolvem uma construção coletiva traz consigo uma série de riscos, também a riqueza da descoberta e da incorporação do sentido do que fazemos. O modo do fazer, de fato, transforma o fazer em um modo de ser.

As categorias definidas para a organização e análise da Matriz Curricular de Referência compreendem: competências, habilidades, bases tecnológicas que possibilitam uma análise das implicações entre si e, ao mesmo tempo, desencadeadas e limitadas a partir do perfil profissional que se deseja formar, definido pelo projeto dos cursos para, então, mapear os conteúdos que podem proporcionar a formação desejada, expressos em forma de ementas. Ressalta-se que as estratégias pedagógicas que irão colocar esse mapa em movimento não estão explicitadas na matriz curricular, mas apenas anunciadas.

A abordagem pedagógica para a implementação desta proposta está aberta para que cada instituição possa implementá-la segundo seu contexto filosófico. Indica-se, com esta metodologia, como organizar uma Matriz Curricular que resulte em termos de uma formação profissional técnica que se pretende coerente, viável, executável e pertinente aos desafios atuais do mundo do trabalho. Portanto, este documento não só traz à tona toda a fundamentação teórica que o sustenta, mas explicita um dos modos de pensar, conceber e desenvolver uma proposta curricular que assegure o mínimo de congruência interna e a possibilidade do exercício de autonomia e flexibilidade que a situação requer. Entende-se, aqui, flexibilidade e complexidade como condições básicas do exercício da construção coletiva.

Logo, por mais que se insista, este texto não dá conta da expressão e do sentido do processo instituído e instituinte desta construção, mas de algumas notas e indicadores básicos a respeito, com o intuito de orientar e otimizar as práticas nessa área, principalmente aquelas da produção de materiais e formação dos agentes de um programa de Formação Profissional Tecnológica na modalidade a distância.

A ênfase desse trabalho foi a construção do perfil profissiográfico do egresso, como ponto de partida e de chegada da formação profissional. 
Ponto de partida porque se faz necessário que fique bem claro, para todos os envolvidos no trabalho, que o objetivo último é a formação do profissional. Assim, uma vez bem estabelecido o perfil, dele e nele, evidenciem-se as competências a serem desenvolvidas por meio das bases tecnológicas enquanto conhecimentos fundantes e necessários ao profissional, presentes no conjunto de ementas das disciplinas arroladas na sua formação.

Ponto de chegada entendendo que, no momento da operacionalização do currículo, isto é, no processo de formação do profissional, as disciplinas e bases tecnológicas constituem-se em meio para o desenvolvimento das competências que asseguram a formação profissional, e não um fim em si mesmas. Desta forma, evitam-se as pulverizações percebidas, geralmente, nas organizações conhecidas como grades curriculares.

Considerando esse pressuposto teórico, os professores coordenadores foram orientados a pensar a construção desta Matriz Curricular de Referência a partir do entendimento de que o perfil profissiográfico deve responder, basicamente, às perguntas: quem é o profissional a ser formado? Que características deve possuir? Qual sua performance como profissional e cidadão?

Ao responder essas questões, entende-se que esse profissional, além de apresentar um conjunto de atitudes e técnicas específicas que caracterizam sua atuação técnico-profissional na respectiva área, também deve apresentar um conjunto de características gerais que o habilitem para o desempenho profissional e que se expressem em valores e princípios de ação. Tais características são: saber relacionar-se, comunicar-se com o público, trabalhar em equipe, ler e interpretar informações técnicas, agir eticamente.

Em se tratando de um curso oferecido na modalidade a distância, o perfil do egresso considera, igualmente, o desenvolvimento de outras habilidades cognitivas. Entre elas, por exemplo, destacam-se as experiências do mundo do trabalho, o estudo autônomo, a reflexão e o pensamento crítico, e o entendimento interdisciplinar.

Esse item - perfil técnico profissional - foi redigido em forma de assertivas descritivas de valores e princípios, desenhando a performance desejada do profissional.

No que diz respeito às competências, busca-se superar a visão estreita das abordagens que limitam o conceito de competência no âmbito exclusivo do fazer. Competente é aquele que sabe fazer bem alguma coisa. A concepção trabalhada nesta 
proposta supera essa visão para um conceito de competência entendido no âmbito das dimensões do humano integrado (valores, cognição, ação). Esse entendimento também sustenta-se pela matriz de Delors (Saber saber, saber ser, saber fazer e saber conviver). Estes princípios não se desenvolvem em ações fragmentadas, nem procede destas. Procede de um entendimento de uma educação integral para um sujeito integrado.

Essa proposta faz-se necessária não apenas em função do atendimento ao enfoque dado pela LDB à Educação Profissional Técnica de Nível Médio, que se desvincula do mero ajustamento da formação profissional às demandas do mercado de trabalho; também pela configuração da produção no sentido atual do mundo do trabalho. Em relatório recente que aborda a discussão da Atualização das Diretrizes Curriculares Nacionais para a Educação Profissional Técnica de Nível Médio, assim se expressa o relator, em relação ao mundo do trabalho, o qual

[...] está a exigir profundas revisões programáticas voltadas para a fuga do obsoleto, de sorte a atender às exigências de profissionais mais polivalentes e capazes de interagir em situações novas e em ambientes de constante mutação. Está acabando essa estrutura rígida de ocupações em postos de trabalho claramente delimitados. As mudanças aceleradas em curso nos processos produtivos e de prestação de serviços profissionais, bem como na organização do trabalho, estão a exigir uma permanente atualização das qualificações, habilitações e especializações profissionais, a partir da identificação clara de perfis profissionais atualizados, que exigem novos itinerários formativos, geradores de alternativas de profissionalização, a partir de níveis cada vez mais elevados de escolarização e de qualificação para o trabalho (CNE/CEB, 2010, p. 4).

Para esse modo de trabalho, continua o relator,

impõe-se a superação do antigo enfoque da formação profissional centrada apenas na preparação para a execução de um determinado conjunto de tarefas, na maior parte das vezes, de maneira rotineira e burocrática. A Educação Profissional Técnica de Nível Médio requer, para além do domínio operacional de um determinado fazer, a compreensão global do processo produtivo, com a apreensão do saber tecnológico presente na prática profissional dos trabalhadores e a valorização da cultura do trabalho pela mobilização dos valores necessários à tomada de decisões profissionais. Nesta perspectiva, não basta apenas aprender a fazer. É preciso que o cidadão trabalhador saiba, também, que existem outras maneiras para aquele fazer e que, portanto, saiba, também, porque escolheu o seu fazer desta ou daquela maneira. Em suma, é preciso que a pessoa detenha a inteligência do trabalho que executa. Para tanto, é necessário que, ao aprender, tenha aprendido a aprender e, com isso, esteja habilitada a 
desempenhar, com competência e autonomia intelectual, suas funções e atribuições ocupacionais, desenvolvendo permanentemente suas aptidões para a vida produtiva (CNE/CEB, 2010, p.12).

Nesse contexto de discussão encontram-se outras manifestações mais contundentes e polêmicas, que tangenciam o conceito de competência como mero fazer e/ou como uma dimensão humana. Quem acompanha a evolução histórica desse conceito percebe que ele se estende há milênios e tem tido, em cada tempo e espaço, alçada a prioridade desta ou daquela concepção.

Para este momento faz-se necessário compreender competência como a dimensão que move a ação humana na realização de determinado propósito, e perceber quais as possibilidades de desenvolvê-la da melhor maneira possível, em se tratando de um processo de formação profissional de nível técnico. Torna-se igualmente importante saber quais valores e saberes são suficientes para o sujeito ser capaz de mobilizar conhecimentos, habilidades e atitudes para atuar em determinada situação, e atingir o desempenho esperado e necessário para a resolução de determinado problema. Isto é, ter a capacidade de flexibilizar e adequar conhecimentos informacionais, habilidades e atitudes à realidade circunstanciada a partir de determinados valores éticos. Ou, conforme enuncia Perrenoud (2008, p. 19), "competência é a faculdade de mobilizar um conjunto de recursos cognitivos (saberes, capacidades, informações, etc.), para solucionar com pertinência e eficácia uma série de situações". Portanto, a competência implica ação, que não é, necessariamente, ação prática (manual), mas que pode ser e é, também, uma ação-reflexiva (ação cognitiva). Assim, a competência é o conhecimento em movimento, em ação, quando da resolução de problemas.

Para Rivilla (2010, p. 18),

[...] as competências básicas são os resultados formativos que os estudantes devem alcançar para poder se realizar e, como seres humanos, participar ativamente da sociedade, serem capazes de aprender ao longo da vida e estar preparados par os desafios da sociedade do conhecimento e para as demandas das futuras ocupações e profissões. A competência básica demanda a integração de saberes essenciais que constituem o núcleo da competência, as formas de agir mediante as quais se aplica o conhecimento e se resolvem os problemas existenciais e profissionais, os valores e as atitudes mais relevantes para conquista da harmonia entre o pensamento e a ação e adquirir um estilo de vida saudável e emocionalmente equilibrada no mundo do trabalho. Os componentes das competências básicas devem servir à pessoa para se envolver e se comprometer com as necessidades da 
realidadesdiversa dos grupos, das culturas e dos diferentes cenários no âmbito da sociedade do conhecimento da globalização e de um processo de interculturalidade.

Na escola, o sujeito não executa propriamente uma competência profissional: ele constrói um habitus, pode apreender um conjunto de valores, conteúdos e estratégias para se tornar competente diante dos desafios de determinada situação existencial, ou de uma área de atuação no mundo do trabalho. Isso envolve questões cognitivas, valorativas, afetivas, operacionais, que podem ser alimentadas nas situações de aprendizagens com perspectivas de serem mobilizadas.

As competências elencadas na proposta da Matriz Curricular decorrem do perfil profissional estabelecido no projeto pedagógico do curso. Nesse sentido, promove a integração das temáticas e dos agentes. Neste estudo tratam-se as competências em três dimensões: atitudinal, cognitiva e procedimental-operacionais ou habilidades.

a) Competência atitudinal é do âmbito do SER (aprender a ser e a conviver). Diz respeito à atitude do sujeito diante da realidade vivenciada. Esta competência implica valores e atitudes, verificáveis pela sua aceitação e internalização no momento das escolhas realizadas. A elaboração destas competências comportamentais atitudinais responde às seguintes questões: o encaminhamento é ético? Leva em conta o impacto socioeconômico-ambiental que o resultado da ação poderá causar? As atitudes do profissional revelam solidariedade, valorização, cooperação, comprometimento com um processo de sustentabilidade? Por quais soluções opta para a resolução de determinado problema? Estas competências nem sempre se expressam em um rol de conteúdos, mas no modo como são organizadas as situações de aprendizagem, e percorrem transversalmente uma Matriz Curricular.

b) Competência cognitiva é do âmbito do saber, do pensar (do saber saber). Diz respeito à capacidade de o sujeito interpretar, rearticular, reelaborar, associar, relacionar e/ou aplicar conhecimentos específicos, seja determinado conhecimento técnico e/ou cultural a uma realidade, no sentido de equacioná-la satisfatoriamente. Responde às seguintes questões: que conhecimentos fundamentais deve o cidadão dominar? Que princípios e/ou conceitos deve 
possuir para que seja possível exercer a profissão de forma eficaz e eficiente? Que condições o sujeito precisa ter para operar com estes conhecimentos? Quais bases tecnológicas Ihes são necessárias?

c) Competências procedimental-operacionais - habilidades referem-se às questões operacionais (o como fazer) nas referências curriculares; são aqui entendidas como habilidades. Estas são do âmbito do FAZER. É a capacidade de o sujeito interagir com seu objeto profissional e em seu contexto. Diz respeito à habilidade, à destreza e ao método, ao manuseio dos instrumentos necessários a determinado fazer. Implica, também, aplicação de regras, técnicas, métodos, habilidade, estratégia, que são verificáveis nas atividades práticas, na ação objetivada.

Essas competências estão assim apresentadas (separadas) meramente por questão didática, pois, na dimensão da objetividade humana, o princípio da ação as objetiva em um mesmo ato. Ou seja, em um movimento implicativo dinâmico e singular:

[...] para el enfoque de la formación basada en la competencia el objetivo de los programas formativos no es, adquirir competencias profesionales (lo cual implica, por supuesto, adquirir conocimientos sobre hechos $y$ conceptos; pero también adquirir conocimientos o saberes sobre procedimientos y actitudes). [...] Porque, em realidad, saber hacer (esto es, desempeñar acciones competentes) requiere saber (esto es, disponer de información y datos, así como de conceptos y teorías que los doten de significado) y saber ser/estar (esto ES, disponer de las actitudes, valores y/o normas que requiere dicho desempeño) (FERNÁNDEZ, 2006, p.11).

O saber-fazer implica e decorre, portanto, do saber o que, do saber por que, deum saber para que e de um saber ser e conviver. Em uma revisão sistêmica rápida encontram-se diversas concepções de competência, cada uma com um enfoque diferenciado, umas mais cientificamente fundadas, outras mais ideologicamente defendidas, mas o que reúne a maioria dos autores é um esforço comum em ressaltar que competência é um modo de ação humana para o qual convergem as dimensões de valores, conhecimento e atitudes mobilizadas em resolver determinado problema, em desempenhar uma ação eficaz, eficiente e relevante (DESAULNIERS, 2010; DURAND, 1990; KUENZER; GRABOWSKI, 
2010; COELHO, 2009; MACHADO, 2003; PERRENOUD, 2010; RIVILLA, 2010; SCHWARTZMAN, 2005.

d) Bases tecnológicas - Indicam claramente o campo de conhecimento do qual emanam os valores, comportamentos e conteúdos que o sujeito precisa elaborar, entender e aplicar em suas ações. Compreendem as bases conceituais, os saberes, as informações, os recursos técnicos, os procedimentos, e as normas específicas da área de atuação.

e) Os temas ou as ementas - As ementas indicam, em itens substanciais e em subitens, os conteúdos que compreendem a disciplina. O elenco das ementas deve atender, distributivamente, ao perfil, às competências, às habilidades e às bases tecnológicas previstas na organização da matriz curricular. Devem ser coerentes em tempo, em extensão e em profundidade em relação aos conteúdos propostos. As ementas que substanciam as disciplinas ofertadas e desenvolvidas nos planos de ensino precisam ser organizadas e distribuídas ao longo do curso de modo orgânico, no sentido horizontal, vertical e transversal, observando os fatores de interdisciplinaridade e suas devidas conexões.

As ementas podem estar distribuídas ao longo do curso conforme a sua organização didática. Se a oferta é periódica e sequencial, com uma única terminalidade, as ementas são apresentadas em uma sequência de ordem de aprofundamento e ampliação dos conhecimentos: dos introdutórios para os gerais, e destes para os específicos. Se a oferta tem caráter modular, então as ementas estarão agrupadas em um conjunto de saberes convergentes, que abrangem formação profissional em uma atividade específica, com caráter de terminalidade e certificações parciais.

Nesta proposta, as ementas são entendidas como temas que se entrecruzam para compor as competências, obrigando o corpo docente agir compartilhadamente. A ordenação, em modo de oferta e evolução de profundidade, fica a cargo da organização dada pelo projeto pedagógico do curso. Ou seja, a mediação para efetivar a oferta define-se pela modalidade de ensino e pela abordagem pedagógica eleita e assumida pelo corpo social envolvido no curso. 


\section{Os procedimentos da pesquisa}

O processo como um todo merece alguns destaques para que o leitor compreenda melhor os resultados. Os passos básicos dessa construção iniciaram-se em novembro de 2009, quando o grupo de pesquisa da UFSC apresentou a proposta de pesquisa: Elaboração de Currículo Referência para os cursos técnicos da Escola Técnica Aberta do Brasil, respondendo à solicitação da coordenação nacional do e-Tec Brasil.

O primeiro passo foi constituir um grupo de estudos, denominado Grupo de Pesquisa Currículo Referência (GPCRF), vinculado ao Grupo de Pesquisa Científica em Educação a Distância ligado ao CNPq. Esse grupo escolheu uma equipe de pesquisadores colaboradores constituída de coordenadores de cursos do sistema e-Tec Brasil, que foram indicados pelos seus pares para realizar a pesquisa. Essa atividade envolveu os principais atores do sistema de implantação do Sistema e-Tec Brasil, os coordenadores de curso e, com eles, concebeu-se uma metodologia para analisar formalmente como se constitui a proposta curricular dos cursos, apropriar-se dessa proposta e reorganizá-la na perspectiva de melhor integração curricular entre os Eixos Tecnológicos e entre os cursos em cada Eixo.

Essa proposta foi apresentada em forma de projeto à Coordenação Nacional do e-Tec e à Comissão Nacional de Acompanhamento e Avaliação do Sistema e-Tec Brasil, que acatou e apoiou sua implementação.

Em dezembro de 2009, em reunião nacional nos dias 12 e 13, em Brasília, o projeto foi apresentado pela coordenação nacional do e-Tec e pela coordenação do grupo de pesquisa da UFSC em uma assembleia de coordenadores gerais de cursos do Eixo Informação e Comunicação, e foi acolhido por unanimidade pelo grupo. Na mesma reunião foi instituído o grupo de pesquisa composto pelos pesquisadores acadêmicos da UFSC e pelos representantes dos cursos do Eixo já mencionado, Informação e Comunicação, que foram eleitos na ocasião. Esse grupo inicial de pesquisadores da UFSC, denominado GPCRF1, e de representantes dos cursos eleitos do Eixo Informação e Comunicação, denominado, inicialmente, de INFCOM e, posteriormente de GPCRF2, foi constituído por um total de 13 pessoas. Esse grupo elaborou a proposta metodológica e definiu os procedimentos essenciais, e reuniu-se diversas vezes entre fevereiro e março de 2010 para elaborar e validar a metodologia. 
A metodologia de análise constituiu-se de uma Matriz organizada pelas categorias indicadas nas Referências Curriculares Nacionais nos seguintes termos: Perfil Profissional, Competências, Habilidades, Bases Tecnológicas e Ementas, conforme exposto anteriormente.

O processo de análise e construção da Matriz curricular proposto compreende um movimento que parte do perfil, desdobrando-se no elenco de competências e habilidades que se sustentam em determinadas bases tecnológicas selecionadas e indicadas como ementas. Esse movimento inverte a prática comum observada na elaboração de currículos, que é a de organizar um curso a partir de um elenco de disciplinas.

O projeto e a metodologia foram levados a um Seminário Nacional, realizado nos dias 15 a 18 de março de 2010, em Fortaleza, para apreciação e aprovação de todos os coordenadores gerais e de cursos do Sistema e-Tec Brasil. Nesse Seminário, o projeto e a metodologia foram aprovados, e foram eleitos mais 48 coordenadores de cursos para compor o grupo de pesquisa. Na ocasião fez-se uma aplicação simplificada da metodologia para reconhecimento, apropriação e entendimento da filosofia de trabalho. Uma filosofia cujo princípio é a construção coletiva de uma proposta de Matriz Curricular de Referência, com o propósito de integrar os Eixos entre si e os cursos dentro do Eixo pelas categorias constitutivas da Matriz Curricular, especialmente das ementas.

A elaboração da Matriz Curricular teve como ponto de partida os projetos pedagógicos dos cursos que constituem o sistema; o Catálogo Nacional de Cursos técnicos e Referenciais Curriculares Nacionais da Educação Profissional de Nível Técnico (BRASIL, 2000).

A partir do referido congresso, o grupo de pesquisa ampliou-se para um grande grupo nacional, constituído por 86 pesquisadores, dos quais 54 são coordenadores de cursos eleitos por seus pares.

O exercício de aprovação da proposta foi realizado coletivamente, guiado por uma metodologia de análise de conteúdo organizada em uma Matriz Curricular de Referência. Os procedimentos básicos foram elaboração, socialização e discussão em fórum virtual e encontros presenciais com todos os representantes. Os trabalhos virtuais foram contínuos por um ano e oito meses, e os presenciais foram desenvolvidos em grupos. Estes grupos estavam organizados em três níveis: grupo 1 - pesquisadores da UFSC, grupo 2 - 
representantes dos eixos tecnológicos, grupo 3 - pesquisadores da UFSC, representantes dos eixos e coordenadores gerais da rede e-Tec Brasil, totalizando 47 encontros.

Esses encontros tiveram o propósito de socialização da produção, envolvendo todos os pesquisadores, todos os coordenadores de cursos, coordenadores gerais, diretores, reitores e equipe da SEED (Secretaria de Educação a Distância) do Sistema e-Tec Brasil.

O esforço contínuo dos pesquisadores concentrados em reconhecer e explicitar o perfil profissional comum em cada curso que constitui a integração entre os Eixos e dos cursos no Eixo, bem como as competências, as habilidades e as bases tecnológicas que o alimentam, foi o ponto forte na construção do urdume básico com que se tece o elenco das ementas.

Por outro lado, a leitura inversa no processo de identificação das ementas, que expressam o desdobramento dessas categorias, buscam distinguir: as que são comuns em relação à formação profissional e modalidade de Educação a Distância; as que são comuns nos diversos Eixos Tecnológicos; as que são comuns entre os cursos de mesmo Eixo; e as específicas que respondem à natureza da formação técnica e/ou a singularidades regionais e/ou sociais e culturais.

\section{Os resultados}

Dos resultados alcançados podem-se destacar alguns avanços importantes, de modo especial na redução da dispersão identificada no estudo anterior (CVMD\UFSC 2009), no qual identificaram-se 2.801 disciplinas a serem oferecidas. Nessa reorganização dos cursos pela perspectiva do Currículo Referência, em uma análise geral, destaca-se que os 54 cursos, incluindo as peculiaridades dos cursos PROEJA, os que atualmente compõem o Sistema e-Tec alcançam um total de 1.036 disciplinas. Somente essa primeira leitura já gera um grande impacto entre os dois cenários, o que inicialmente se compõe de 165 cursos e 2.801 disciplinas, e este que se compõe de 47 cursos e 1.036 disciplinas, para atender à mesma demanda do Sistema e-Tec Brasil. Na perspectiva da integração do sistema de formação profissional de nível técnico, o Currículo Referência gera outros impactos significativos, tanto em relação ao processo de integração e constituição de uma identidade para os cursos, 
quanto para melhor sistematização na produção de materiais para eles na modalidade a distância.

Com essas considerações formalizadas pode-se acreditar que, no início do século XXI, a Educação Profissional de nível médio, na modalidade a distância, torna-se uma possibilidade e um desafio capaz de promover o conhecimento tecnológico necessário para que dele o indivíduo se aproprie, incorporando-o em seu saber profissional, bem como cultive os valores inerentes à cultura do trabalho, na convivência do dia a dia do seu exercício profissional, como cidadão trabalhador, responsável e competente. É preciso que ele tenha o domínio da inteligência e da prática, e execute-a com a devida competência. É por essa perspectiva que se orienta o desenvolvimento da pesquisa para elaborar uma Matriz Curricular de Referência para o Sistema e-Tec Brasil.

Além da legislação específica, fundamentaram este estudo: as Referências Curriculares Nacionais para a Educação Profissional Técnica de Nível Médio (BRASIL, 2010); o Catálogo Nacional de Cursos Técnicos (BRASIL, 2008); Anais e deliberações I e II da Conferência Nacional de Educação Profissional e Tecnológica (CONFETEC, 2007).

As análises do processo e dos resultados deste trabalho estão apresentadas em duas publicações: uma preliminar, que ficou em consulta pública para a comunidade por 60 dias; e uma publicação final de 479 páginas, que contém 57 matrizes curriculares. Esse currículo referência foi lançado em um grande seminário realizado em Curitiba, que reuniu aproximadamente 300 coordenadores e professores dos cursos que estavam sendo ofertados. Na ocasião foram distribuídas 300 cópias impressas acompanhadas de DVD, além de serem disponibilizados no site oficial da pesquisa www.etec.ufsc.br. Na ocasião foram entregues 500 cópias ao Ministério da Educação, que acolheu o resultado emitindo uma nota técnica de orientação e apoio.

O trabalho de pesquisa teve como princípio básico a construção coletiva, que pressupõe investigação e interferência ao mesmo tempo. Considera-se como resultado não só os produtos publicados, também as transformações geradas no processo, as quais foram de uma contundência inigualável, pois a evolução teórico-metodológica, o aprimoramento e cooperação que o grupo de pesquisadores desenvolveu, nesse período de mais de um ano de trabalho coletivo, transformaram o modo pelo qual cada um e todos os envolvidos se inserem no sistema. 
A realização dessa construção coletiva compartilhada leva a uma perspectiva de transformação de possibilidades infinitas, que não se encerra aqui; contudo, aqui se inicia.

\section{Referências}

BOURDIEU, Pierre. Os doxósofos. In: THIOLLENT, Michel J. M. Crítica metodológica, investigação social \& enquete operária. São Paulo, Polis, 1987.

BRASIL, Ministério da Educação. Secretaria de Educação Profissional e Tecnologia. Atualização das Diretrizes Curriculares Nacionais para a Educação Profissional Técnica de Nível Médio. Versão preliminar para debates na Audiência Pública Nacional. 2012.

. Conselho Nacional de Educação. Câmara de Educação Básica. Resolução no 4, de 13 de julho de 2010. Define as Diretrizes Curriculares Nacionais Gerais para a Educação Básica. Disponível em:

$<$ http://portal.mec.gov.br/index.php?option=com content\&view=article\&id=14906\&/temid $=866$ > . Acesso em: 10 set. 2010 .

. Decreto no 5.154, de 23 de julho de 2004. Regulamenta o § 20 do art. 36 e os arts. 39 e 41 da Lei no 9.394, de 20 de dezembro de 1996, que estabelece as diretrizes e bases da educação nacional, e dá outras providências. Disponível em: <http://www.planalto.gov.br/ccivil 03/ ato2004-2006/2004/decreto/D5154.htm>. Acesso em: 10 set. 2010.

. Resolução no 3, de 9 de julho de 2008. Dispõe sobre a instituição e implantação do Catálogo Nacional de Cursos Técnicos de Nível Médio. Disponível em: <http://portal.mec.gov.br/setec/arquivos/pdf/rceb003 08.pdf>. Acesso em: 10 set. 2010.

. Catálogo Nacional de Cursos Técnicos. Brasília: Junho, 2008. Disponível em: <http://www.etec.ufsc.br/file.php/194/Referenciais Nacionais/Catalogo Nacional de Curs os Tecnicos.pdf $>$. Acesso em: 9 out. 2010.

Conselho Nacional de Educação Câmara de Educação Básica. Resolução no 4, de 13 de julho de 2010. Disponível em: <http://www.fnde.gov.br/index.php/rockres2010/4766-res01913072010anexo01/download>. Acesso em: 10 set. 2010.

Decreto n. 6.301, de 12 de dezembro de 2007. Institui o Sistema Escola Técnica Aberta do Brasil - e-Tec Brasil. Disponível em: <https://www.planalto.gov.br/ccivil_03/_ato2007-2010/2007/decreto/d6301.htm> Acesso em: 10 set. 2010.

. Decreto no 2.208, de 17 de abril de 1997. Revogado pelo Decreto no 5.154, de 2004 Regulamenta o § 2 do art. 36 e os arts. 39 a 42 da Lei $n \circ 9.394$, de 20 de dezembro de 1996, que estabelece as diretrizes e bases da educação nacional. Disponível em:

< http://www.planalto.gov.br/ccivil 03/decreto/D2208.htm> Acesso em: 10 set. 2010. 
. Decreto no 6.302, de 12 de dezembro de 2007. Institui o Programa Brasil Profissionalizado. Disponível em: <https://www.planalto.gov.br/ccivil 03/ ato20072010/2007/decreto/d6302.htm> Acesso em: 9 out. 2010.

Lei no 9.394, de 20 de dezembro de 1996. Estabelece as diretrizes e bases da educação nacional. Artigo 80.. Disponível em: $<$ http://portal.mec.gov.br/seed/arquivos/pdf/tvescola/leis/lein9394.pdf $>$. Acesso em: 10 set. 2010.

. Parecer Conselho Nacional de Educação Câmara de Educação Básica no 11/2008. Proposta de instituição do Catálogo Nacional de Cursos Técnicos de Nível Médio. Disponível em: $<$ http://www.etec.ufsc.br/file.php/194/Referenciais Nacionais/Catalogo Nacional de Curs os Tecnicos.pdf >. Acesso em: 09 out. 2010.

Portaria no 870, de 16 de julho de 2008. Referencial comum às denominações dos Cursos Técnicos de Nível Médio. Disponível em: <http://portal.mec.gov.br/dmdocuments/pceb014 09.pdf>. Acesso em: 10 set.2010.

Referenciais de qualidade de EaD de cursos de graduação a distância. Disponível em:

<http://portal.mec.gov.br/seed/index.php?option=content\&task=view\&id=62\&ltemid=191> . Acesso em: 09 out. 2010.

Secretaria de Educação Profissional Tecnológica. Conferência Nacional de Educação Profissional e Tecnológica. Anais e deliberações da I Conferência Nacional de Educação Profissional e Tecnológica. Brasília, 2007.

. Secretaria de Educação Profissional e Tecnológica. Educação Profissional Técnica de Nível Médio Integrada ao Ensino Médio. Documento Base. Brasília, 2007.

. Parecer Conselho Nacional de Educação Câmara de Educação Básica № 11/2008. Proposta de instituição do Catálogo Nacional de Cursos Técnicos de Nível Médio. Disponível em:

<http://www.etec.ufsc.br/file.php/194/Referenciais Nacionais/Catalogo Nacional de Curs os Tecnicos.pdf>. Acesso em 09/10/2010.

. Secretaria de Educação Profissional Tecnológica Conferência Nacional de Educação Profissional e Tecnológica. Anais e deliberações da I Conferência Nacional de Educação Profissional e Tecnológica. Brasília, 2007.

BRASIL. Ministério da Educação/SETEC. Currículo Referência: políticas públicas para a educação profissional e tecnológica. Brasília: MEC, 2004.

BRASIL. Ministério da Educação/SETEC/SEED. Edital de Seleção no 01/2007. Edital de Seleção de Projetos de Cursos de Educação Profissional Técnica de Nível Médio, na 
Modalidade de Educação a Distância. Disponível em:

<http://www.etec.ufsc.br/file.php/194/edital etec2007.pdf>. Acesso em: 10 set. 2010.

BRASIL. Secretaria de Educação Fundamental. Parâmetros curriculares nacionais: introdução aos parâmetros curriculares nacionais. Brasília, 1997. Disponível em: <http://portal.mec.gov.br/seb/arquivos/pdf/livro01.pdf>. Acesso em: 09 out. 2010.

COELHO, M. P. C; FUERTH, L. R. A Influência da gestão por competência no desenvolvimento profissional. Cadernos de Administração. v. 1, n. 03, jan./jun. 2009.

DELORS, J. et al. Educação: um tesouro a descobrir. São Paulo: Cortez, 1998

DESAULNIERS, Julieta Beatriz Ramos. (Org.). Formação \&trabalho \& competência. Porto Alegre : Edipucrs, 2010.

FERNÁNDEZ, P. P. Formación de trabajadores y trabajadoras de educación profesional y tecnológica: saberes, metodologias y práticas pedagógicas. FóRUM MUNDIAL DE EDUCAÇÃO PROFISSIONAL E TECNOLÓGICA: EDUCAÇÃO, DESENVOLVIMENTO E INCLUSÃO. 2009, Brasília. Anais... Brasília: MEC, 2006

KUENZER, Acácia Zeneida; GRABOWSKI, Gabriel. Educação profissional: desafios para a construção de um projeto para os que vivem do trabalho. Perspectiva, Florianópolis, v. 24, n. 1, p. 297-318, jan/jun. 2006. Disponível em: <http://www.perspectiva.ufsc.br>. Acesso em: 10 set. 2010.

MACHADO, Nilson José. As Competências para ensinar no século XXI. A formação dos professores e o desafio da avaliação. Porto Alegre: ArtMed, 2003.

PERRENOUD, P. Construindo competências. Entrevista com Philipe Perrenoud por Paola Gentile e Roberta Bencini. Disponível em $<$ http://aprenderdireito8.blogspot.com/2008/12/construindo-competncias-entrevistacom.html>. Acecesso em: 10 set. 2008.

RIVILLA, A. M. (Org.). Formação e desenvolvimento das competências básicas. Madri: IBPX, 2010.

SACRISTÁN GIMENO, J. O currículo: uma reflexão sobre a prática. Porto Alegre: ArtMed, 1998.

SCHWARTZMAN, S. A sociedade do conhecimento e a educação tecnológica. Trabalho realizado por solicitação do Serviço Nacional de Aprendizagem Industrial - SENAI, Departamento Nacional. Janeiro de 2005.

RECEBIDO EM 30 DE SETEMBRO DE 2016.

APROVADO EM 31 DE OUTUBRO DE 2016. 